\title{
Developing a culturally relevant bioethics for Asian people
}

Michael Cheng-tek Tai and Chung Seng Lin Chungshan Medical and Dental College, Taichung, Taiwan

\begin{abstract}
Because of cultural differences between East and West, any attempt at outright adaptation of Western ideas in Asia will undoubtly encounter problems, if not rejection. Transferring an idea from one place to another is just like transplanting an organ from a donor to a recipient - rejection is to be expected. Human cultures respond to new ideas from different value systems in very much the same way.

Recently, biomedical ethics has received much attention in Asia. Fundamental advances in medicine have motivated medical scientists to look at the ethical issues arising from this progress. Will the principles upheld by the bioethicists in the West meet the challenge in Asia?

This article argues that Asian bioethicists must develop a bioethics responding to their own cultural contexts. If Western principles are adopted, then they must be re-interpreted and even modified, if necessary, in light of Asian beliefs.

(Fournal of Medical Ethics 2001;27:51-54)
\end{abstract}

Keywords: Bioethics; transplantation; Asianisation

\section{Introduction}

Human-heartedness has been at the centre of Asian civilisation throughout history. Benevolence and compassion are the two magic words in Asian cultures. Asian people are not as individualistically oriented as their counterparts in the West, especially in their demands for self actualisation. Historically, family, community or the greater self always carry a greater weight in Asian value systems than individuals. Since the re-emphasis of the importance of bioethics in the twentieth century took place in the West, ${ }^{1}$ Asian people have the impression that bioethics is a Western product. For instance, when discussing the theoretical foundations of bioethics, we refer to John Mill's utilitarianism and Kant's deontologism. Are we transplanting these Western concepts to Asia? Are there any hidden bioethical thinkings in the East waiting to be explored? Can Asians develop a concept of bioethics based on their traditional cultures?

These questions are legitimate. In order for bioethical principles to be respected, Asians must attempt to discover the traditional values of their own bioethical teachings and develop a bioethics culturally relevant to them. At least they should attempt to interpret the principles of biomedical ethics from the perspective of Asian beliefs.

\section{Medical ethics in Asian cultures}

Few people are aware that Asian cultures had an interest in medical ethics long ago. In China, we find writing on medical ethics as early as the 2 nd century BCE. Sun Szu-miao of China had already written the "Do's and Don'ts" for physicians in the seventh century. ${ }^{2}$ We can also trace the code of ethics in Hindu tradition as far back as Vedic times. $^{3}$ These teachings were based on broader cultural frameworks, such as Confucianism or Brahmanism.

From Sun Szu-miao's writings, we can identify three classical Chinese virtues: humanness, compassion and filial piety. Although Sun has been regarded as a Taoist, his writings reflected significant influence by Buddhist and Confucian thought, which provided the background for many other Chinese medical ethics. ${ }^{4}$ From the Chinese classics we find that the Chinese had accepted that the human capacity to struggle against death is limited. For instance, Chuang-tzu saw death as a part of nature, to which humans should return, thus confronting it with ease and courage himself. There is also a constant concern for the care given to the poor in Confucian tradition. Here we find similarities between Confucian ethics and the principles of Western biomedical ethics, but differences in their emphases and interpretations.

The most important texts in ancient Indian medical ethics are the Caraka Samhita, which is part of Vedic religious writings on medicine and the Susruta Samhita. The former was written about the first century $\mathrm{AD}$ and stated that the physician should lead the life of a celibate, speak only the truth, eat no meat, be free from envy and carry no arms. Physicians should endeavour to relieve patients, should not desert or injure them and should never cause another's death. Physicians should be committed to helping their patients as in Hippocratic ethics. But when facing an impending death, in keeping with the notion of benevolence, physicians were not to tell patients of their terminal illness. The Susruta refers to the rites of the atharvan, who was a medicine man in a domestic setting, aiding individuals in their homes to alleviate personal and family crises.

The Vedic tradition was concerned either with the limited resources of medical care or with human worthiness of receiving care. The Carake states: "No persons who are hated by the king or who are haters of the king or who are hated by the public or who are haters of the public, shall receive 
treatment. Similarly, those who have not vindicated their honour, those who are on the point of death and similarly women who are unattended by their husbands or guardians shall not receive treatment". ${ }^{6}$ This is in sharp contrast to JudaeoChristian and Chinese medical ethics. The doctrine of Karma in Hindu religious thought played a role in this rule.

\section{Autonomy and justice: West and East}

Principle is a general truth or a rule which is basic to other truths. The literature in biomedical ethics in the last fifteen or twenty years has identified several moral principles, such as: respect the wishes of competent persons; do no harm to others, including a prohibition against killing and cruel treatment; benefit others; produce a net balance of benefit over harm; distribute benefit fairly; keep promises and contracts; disclose information; respect privacy, and protect confidential information, etc. These obligations are stated as principles or as rules. Some obligations are regarded as primary and fundamental, whereas others are secondary and derivative. Among all these principles and rules, Beauchamp and Childress have jointly recognised autonomy, non-maleficence, beneficence, and justice as primary principles which have generally been accepted as the four basic principles of medical ethics.

These principles are not foreign to Asians, especially beneficence and non-maleficence: Asian sages such as Confucius and Sakymuni all taught the same Golden Rule: "Do unto others as you would have them do unto you"; or in a Confucian expression: "Do not do to others what you don't like others to do to you". This consensus would seem to mean that we have established that there is a universally accepted truth at the root of biomedical principles. Unfortunately, it is not quite so simple. The same Golden Rule is upheld both in the West and the East. Yet, in the applications of these principles to actual situations, different interpretations surface, especially as concerns the principles of autonomy and justice.

The best known definition of autonomy comes from Emmanuel Kant, the eighteenth century German philosopher, who said that all rational beings have the capacity to act in a consistent moral manner and they should be allowed to do so. What Kant is saying is that every person has the ability to understand notions of right and wrong and to act accordingly. It does not mean that everyone will agree on what is right nor that once understood, each person will always do what is right. But this belief is central in that it points to and safeguards the right of every person to make his or her decisions and to have those decisions respected by others. Applying this to the health and wellbeing of patients means that the patient himself is the primary decision maker with respect to his own health and medical care. Deriving from this principle is the concept of "informed consent". Consent is present when two or more people agree in conscience on something. In medical procedure it implies that both doctor and patient must consent before a particular course can be followed. Each patient's autonomy must be respected because each has a right to decide whether to accept treatment or to refuse to continue with treatment; and each patient has the right to have that decision respected even if it is not in his best interest to do so.

Confucian ethics has a very different understanding of this self determination. In a society where the family is the centre of all attention, autonomy becomes collective rather than individualistic. ${ }^{7}$ The centre of each person's life is not himself or herself but the family. Thus, autonomy can only be spoken of as a collective right rather than an individual privilege. Although a family is composed of many members, community starts not with the individual but with the unit of the family, which becomes the base of a macro-vision of Confucian tradition for a harmonious universe. Each person exists for the greater common good, for the greater good of the community of many different individuals.

We can see this collective autonomy in practice in Taiwan. When a patient has been diagnosed with terminal cancer, the first person to be notified is often not the patient himself, but the head of the family, such as the father or the husband. He then will confer with other family members to see what course must be taken. After the decision is made, the patient may be advised in a disguised way, to ease his anxiety. Furthermore, when considering different treatment options, the family members, especially husband or father, are again consulted first rather than the patient himself/herself. When the patient is a father or husband, the family member who becomes the spokesperson for the family, with whom physicians consult, is usually the eldest son.

\section{Longevity and immortality}

From a Western individualistic perspective, this collective autonomy violates the principle of autonomy. Not so, however, from the Confucian point of view. Here, the head of the family, in consultation with other members, must decide what is the best for the patient for filial piety's sake. In Folk-Taoist thinking, longevity and immortality are the two chief goals of life. Since immortality is the privilege of the Spiritual Man (Hsien) only, longevity becomes the goal of commoners. Thus, the longer a person's life is prolonged, the more filial or loving the family is and the better for the patient. Should we give up treating a person with terminal cancer? Should a person be put to death even if he or she so desired and requested? According to Chinese tradition, life is too sacred to be abandoned or shortened.

Justice is understood in the Confucian tradition as $Y i$ (righteousness). Righteousness means the "oughtness" of a situation. Using Kant's phrase, it is a "Categorical Imperative". Everyone in society has certain things which they ought to do. If, however, one does them only because of other non-moral considerations, then even though one 
does what one is supposed to do, one acts for profit rather than from oughtness. Righteousness and profit are opposing terms in Confucian teachings. Confucius saw justice not so much as fairness but rather as oughtness. ${ }^{8}$ Confucius believed that every person is endowed with certain responsibilities by his station in life, which concept is called "Rectification of Names". If names are not rectified, Confucius said, then language will not be in accordance with truth. If language is not in accordance with truth, then things cannot be accomplished. Thus, he said: "Let the ruler be ruler, the minister minister, the father father and the son son", meaning that each person is given a certain task to perform and he must do it accordingly. Such is justice.

Applying Confucian teaching to medical ethics, we see the role of the physician is to heal for conscience's sake rather than for profit. Thus, he must heal regardless of the patient's social status or financial circumstances. Confucius is known as a teacher for all classes of people, and just so, must a physician too be a healer for all classes of people. This understanding of treating patients equally corresponds to Hippocratic teaching. But Confucian tradition has one more emphasis: the responsibility of the patient towards himself. Confucius said that our body is a gift from our parents; therefore, we must take good care of it rather than abuse it. Whoever fails in this duty is unrighteous because he does not comply with the mandate of heaven Accordingly, we can ask whether a heavy smoker who refuses to stop has the right to a heart transplant or a drug addict the right to Medicare. These are hard questions to answer, but in a situation of meagre medical resources, it may be a good question to ponder. This emphasis on righteousness seems to echo the Vedic view.

The Vedic writing in the Sahmhita stated a similar principle: a hater and a threat to the public has no right to receive any medical care. This statement may sound cruel for it denies the equality of all Justice, however, has many different meanings and can be understood in many different ways. For instance, the egalitarian theory of justice emphasises equal access to primary goods. Marxist theory emphasises need, libertarian theories emphasise rights to social and economic liberty and utilitarian theories emphasise a mixture of such criteria so that public and private utility are maximised.

To define more clearly the meaning of justice, two kinds of criteria, formal justice and material justice, may be defined. Regardless which criterion of justice we believe in, we can never strike a perfect balance, a perfect justice. Should justice be understood as fairness or "what is deserved"? Confucian and Vedic traditions provide a new insight for us. Each should receive equal rights, but when rights are abused, can a real justice be preserved? Justice, from the Asian point of view is a matter of reciprocity.

\section{Are principles universally binding or culturally relevant?}

Ethical theories differ not only according to which aspect of human action they emphasise and which moral principles and rules they propose, but they also differ in respect of the foundation they offer for those principles and rules. Even among proponents of the same principles and rules, there is wide disagreement about what those principles and rules imply for particular cases, because of disputes about their meaning and weight.

Beauchamp and Childress argue that the principles they identify, beneficence, non-maleficence, autonomy and justice, along with such derivative rules as veracity, fidelity, privacy and confidentiality are only prima facie binding. In other words, these principles and rules have to be weighted and balanced in decision making. ${ }^{9}$ On the basis of this statement we can confidently suggest that there can be different sets of principles and rules for different peoples in different cultural settings. We may all accept the principles promoted by Beauchamp and Childress, yet in application to concrete situations, tradition should not be ignored or overlooked. Principles of biomedical ethics, thus, cannot be universally binding, but must be culturally relevant.

\section{Conclusion}

In applying biomedical ethical principles to the actual medical situations in Asia, cultural elements must be considered. To give a concrete example, the rule of informed consent must not refer to the patient alone. The patient's family should also be consulted before a definite action is taken

By the same token, justice cannot be defined as straightforward fairness. A person's responsibility to look after his own health should also be brought into consideration. Justice has to be materialistic rather than formal even though formal justice appears to be fairer than other forms of justice. How to strike a balance between these two kinds of justice provides opportunity for further study.

Life evolves in a community and expresses itself in culture. A community, large or small, is in trouble if its members are not willing to be united in loving and suffering together. The disintegration of community in modern civilisation, out of touch with real humanity by its over-emphasis on individualism, should be a matter of grave concern. A bioethics without cultural concern will lose touch with community. Since Asia has rooted itself so deeply in community-oriented life, our bioethics cannot ignore this characteristic. Developing culturally relevant principles of bioethics has become a major task for Asians in the new millenium.

Michael Cheng-tek Tai, PhD, is Professor of Bioethics and Medical Humanities and Head of the Division of General Education, Chungshan Medical and Dental College, Taichung,Taiwan. Chung Seng Lin, MD, is President and Professor at Chungshan Medical and Dental College, Taichung, Taiwan.

\section{References}

1 Parsons AR, Parsons DH. Health care ethics. Toronto: Wall and Emerson, 1992: 3-10. 
2 Ho Chao-hiung. Zong-kuo I de su (History of Chinese medical morality). Shiang-hai: Shiang-hai Medical University Press, 1988. Also see: Unschuld Paul U: Medical ethics in Imperial China : a study in historical anthropology. Berkeley: University of California Press, 1979

3 Keith AB. The religions and philosophy of the Vedas and Upanishads vol 1. Cambridge, Mass: Harvard University Press, 1925: 290.

4 Veatch RM. Medical ethics. Boston: Jones and Bartlett, 1989: 17.
5 Nelsen NC Jr. Religions of the world. New York: St Martin's Press, 1988: 119.

6 See reference $4: 18$.

7 Tai M. Principles of medical ethics and Confucian relationship. Religious Studies and Theology 1997;16:61.

8 See reference 7: 60 .

9 Beauchamp TL, Childress J. Principles of biomedical ethics [2nd ed]. New York: Oxford University Press, 1979: 14-17.

\section{News and notes}

\section{Journal of Medical Ethics - http://www.jmedethics.com}

Visitors to the world wide web can now access the Fournal of Medical Ethics either through the BMJ Publishing Group's home page (http:// www.bmjpg.com) or directly by using its individua URL (http://www.jmedethics.com). There they will find the following:

- Current contents list for the journal

- Contents lists of previous issues

- Members of the editorial board

- Subscribers' information

- Instructions for authors

- Details of reprint services.
A hotlink gives access to:

- BMJ Publishing Group home page

- British Medical Association website

- Online books catalogue

- BMJ Publishing Group books.

The web site is at a preliminary stage and there are plans to develop it into a more sophisticated site. Suggestions from visitors about features they would like to see are welcomed. They can be left via the opening page of the BMJ Publishing Group site or, alternatively, via the journal page, through "about this site". 